\title{
Delineation of structures favourable to groundwater occurrence employing seismic refraction method - A case study from Tiruvuru, Krishna district, Andhra Pradesh
}

\author{
N Sundararajan*, Y Srinivas*, M Narasimha Chary ${ }^{+}$, G Nandakumar* and \\ A Hanmantha ChaRY* \\ ${ }^{*}$ Centre of Exploration Geophysics, Osmania University, Hyderabad 500 007, India. \\ + Atomic Minerals Directorate for Exploration and Research, Department of Atomic Energy, Begumpet, \\ Hyderabad 500 016, India.
}

The contacts associated with an outlier in biotite gneiss and sandstones near Tiruvuru, Krishna district, Andhra Pradesh which are generally favourable for groundwater occurrence were investigated employing refraction seismic method. Results were examined by correlating the signals with local geology, bore well data and other available information in order to improve the reliability of interpretation.

\section{Introduction}

The groundwater occurrence in geological contacts between two different formations has given ample scope for exploring it near Tiruvuru, Krishna district. A.P. The presence of thick impermeable clayey soil over sandstone has limited the recharge of aquifers from the ground surface. In such areas, the contacts between sandstone and biotite gneiss have become the loci for recharge. Hence, locating such contacts and associated potential aquifers by refraction seismic studies assumes significance in groundwater exploration.

No specific or detailed geophysical surveys were carried out earlier in the area to locate groundwater reserves except the regional magnetic surveys by Murthy et al (1982) and (1983). Further, the Geological Survey of India (GSI) has carried out some preliminary seismic surveys to determine the lateral extension of the outlier located near Tiruvuru (Sarma et al 1968). The Central Ground Water Board has undertaken geophysical surveys employing seismic and electrical methods, wherein the low velocity and moderate resistive zones were identified in the crystalline formations underlying the sandstone (Ramam et al 2000).
Thus, the Tiruvuru outlier and its contacts form an interesting area for mapping of structures favourable for groundwater prospecting. Accordingly, an investigation employing seismic refraction method along a selected traverse was carried out. Deep aquifers of fractured biotite gneiss within the bedrock below sandstone have been investigated for possible potential groundwater locations. The acquired data were interpreted and correlated with available geology, and other information including bore well data.

\section{Hydrogeology}

The area of investigation lies between latitudes $17^{\circ} 01^{\prime} 15^{\prime \prime} \mathrm{N}$ and $17^{\circ} 07^{\prime} 30^{\prime \prime} \mathrm{N}$ and longitudes $80^{\circ} 32^{\prime} 30^{\prime \prime} \mathrm{E}$ and $80^{\circ} 37^{\prime} 30^{\prime \prime} \mathrm{E}$ near Tiruvuru (figure 1). Here, a tiny outlier in metamorphic crystallines (biotite gneisses) of Archeans with younger Gondwana sediments (Kamthi sandstones) is reported by Ziauddin (1954). The area exhibits biotite-muscovite gneisses with soil cover of 1.5 to $3 \mathrm{~m}$ (Krishnan 1960 and Ramamohan Rao 1979). Rocks like schistose, quartzo-felspathic gneisses, magmatised gneisses, amphibolites, acid

Keywords. Groundwater; biotite gneiss; geological contact; sandstones; refraction seismics; low velocity. 


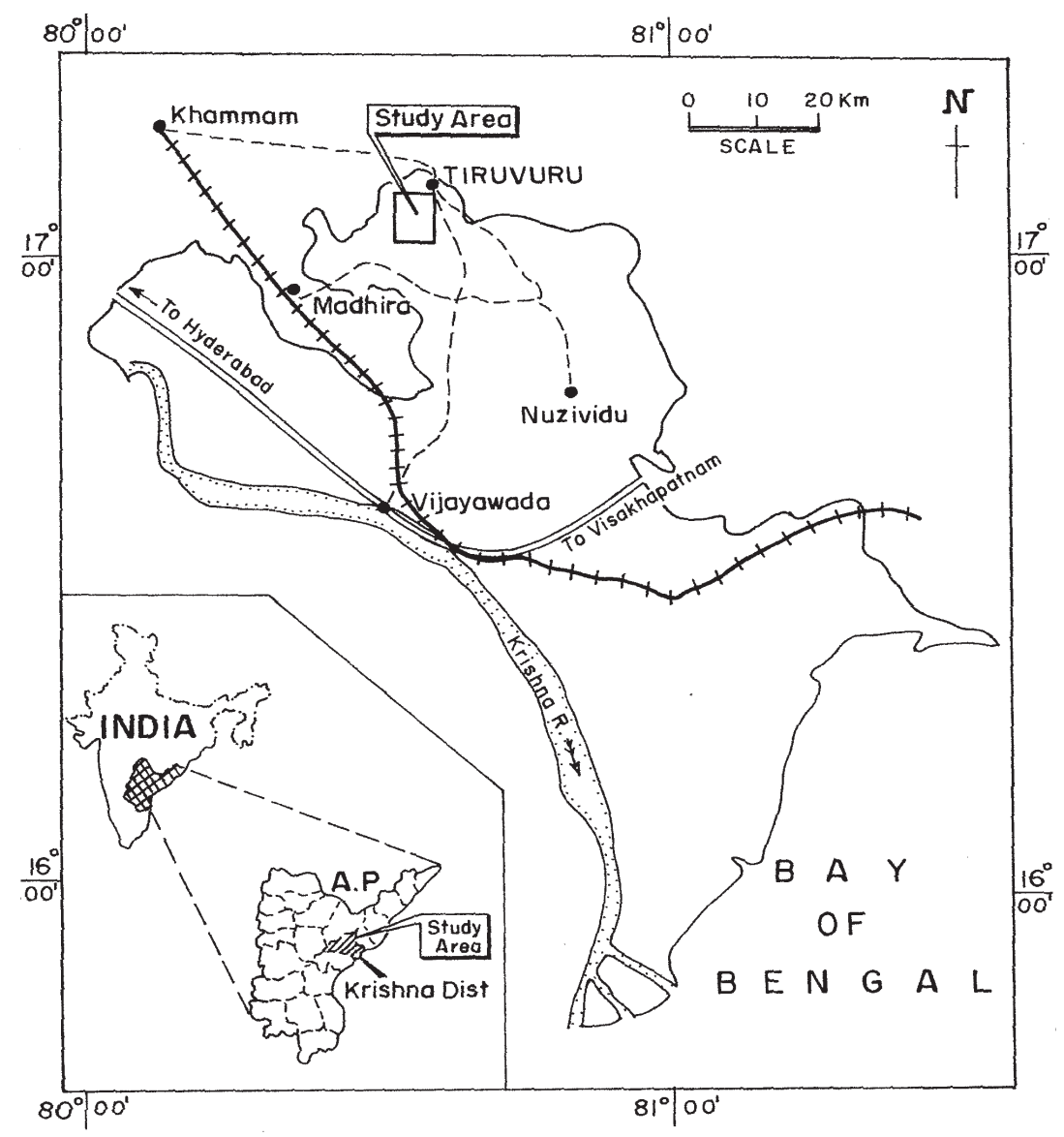

Figure 1. Location map of Tiruvuru and adjoining area, Krishna district, Andhra Pradesh, India.

and mafic granulites, basic intrusives, pegmatites etc. are also found. The most important unexposed geological feature of the area is the contact between sandstone and biotite gneiss. It was reported by Venkataraman (1961) that the Kamthi sandstone occurs as an outlier in biotite gneiss over an area of about $17 \mathrm{sq} \mathrm{km}$ striking EW.

Occurrence of groundwater is common in Precambrian gneisses and lower Gondwana sediments (Kamthi sandstones) in the area of investigation (Shyam Prasad 1995). The water-bearing properties vary from one rock type to another rock type. Biotite gneisses are compact and less susceptible to weathering. The thickness of weathered zone ranges between 6.0 and $12.0 \mathrm{~m}$. These formations do not possess primary porosity and tend to become groundwater repositories with the development of secondary porosity and permeability due to weathering and fracturing. Groundwater in these rocks occur under water table conditions and is restricted to weathered, fractured and jointed horizons. The area is extensively developed by dug wells and shallow bore wells. Dug wells tapping this zone vary in depth from 5 to $11 \mathrm{~m}$ and the depth to water table varies from 2.3 to $6.8 \mathrm{~m}$ below ground level. The yield of these wells in weathered, fractured and jointed zones of this formation ranges from 25 to $150 \mathrm{~m}^{3}$ /day.

In the Tiruvuru area, Kamthi sandstone of lower Gondwana (10 to $50 \mathrm{~m}$ of thickness) are covered by thick soil of ferruginous clay (2 to $4 \mathrm{~m}$ thick), indicating poor groundwater potential within these rocks. A majority of the open wells in the area tap unconfined aquifer down to 8 to $13 \mathrm{~m}$. Depths to water table in these wells vary from 2 to $5 \mathrm{~m}$ and the yield ranges between 60 and $200 \mathrm{~m}^{3}$ /day. Deeper aquifers are yet to be tapped in the area. Some of the dug wells have penetrated the contact of biotite gneiss which are found to yield moderate amounts of groundwater.

\section{Geophysical investigations and data acquisition}

Advent and advancement of tools and techniques in data acquisition, processing and interpretation, pave the way for seismic method to play a major role in groundwater exploration. Refraction seismic 


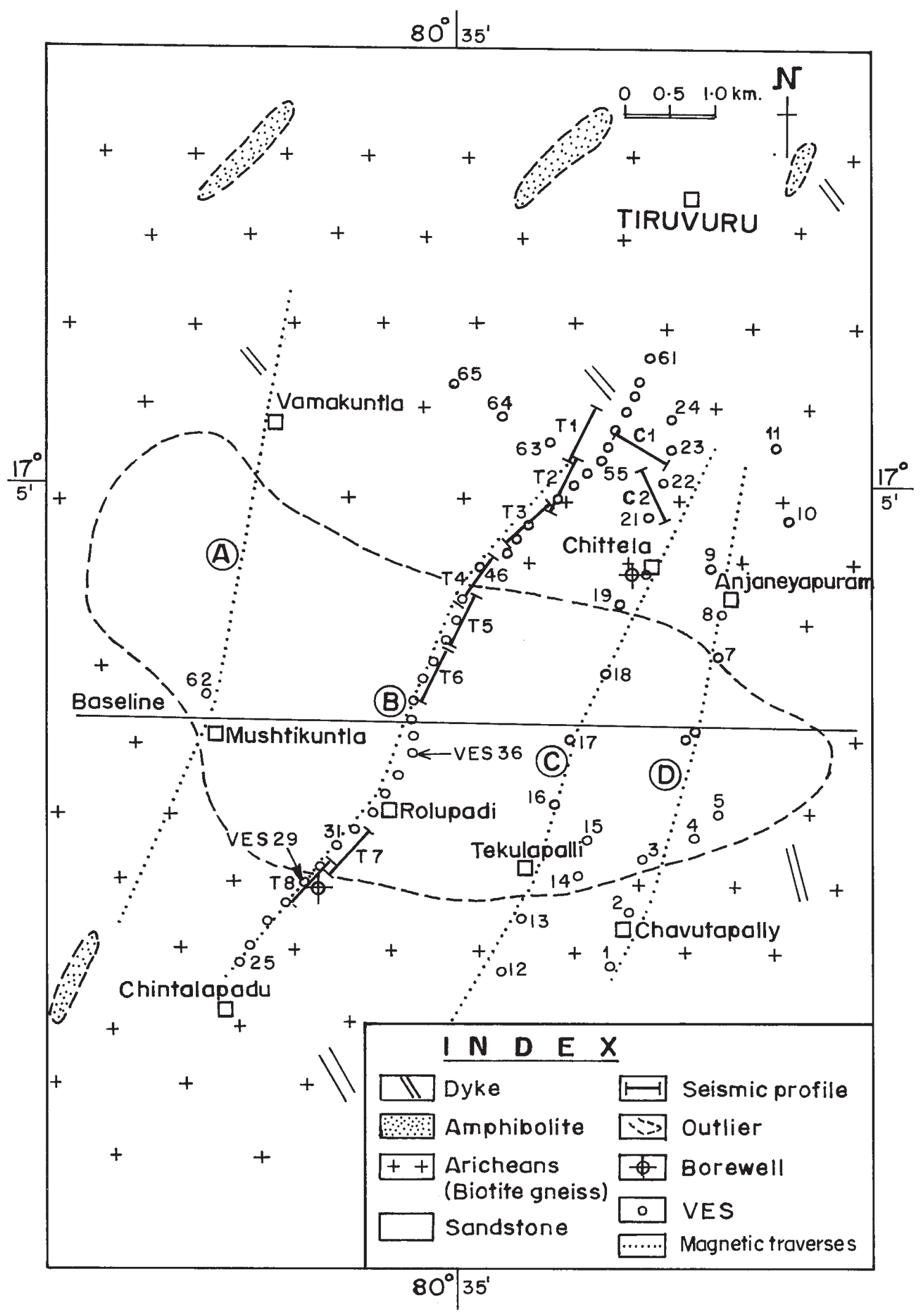

Figure 2. Geology and layout plan of geophysical surveys in the area of investigation. 


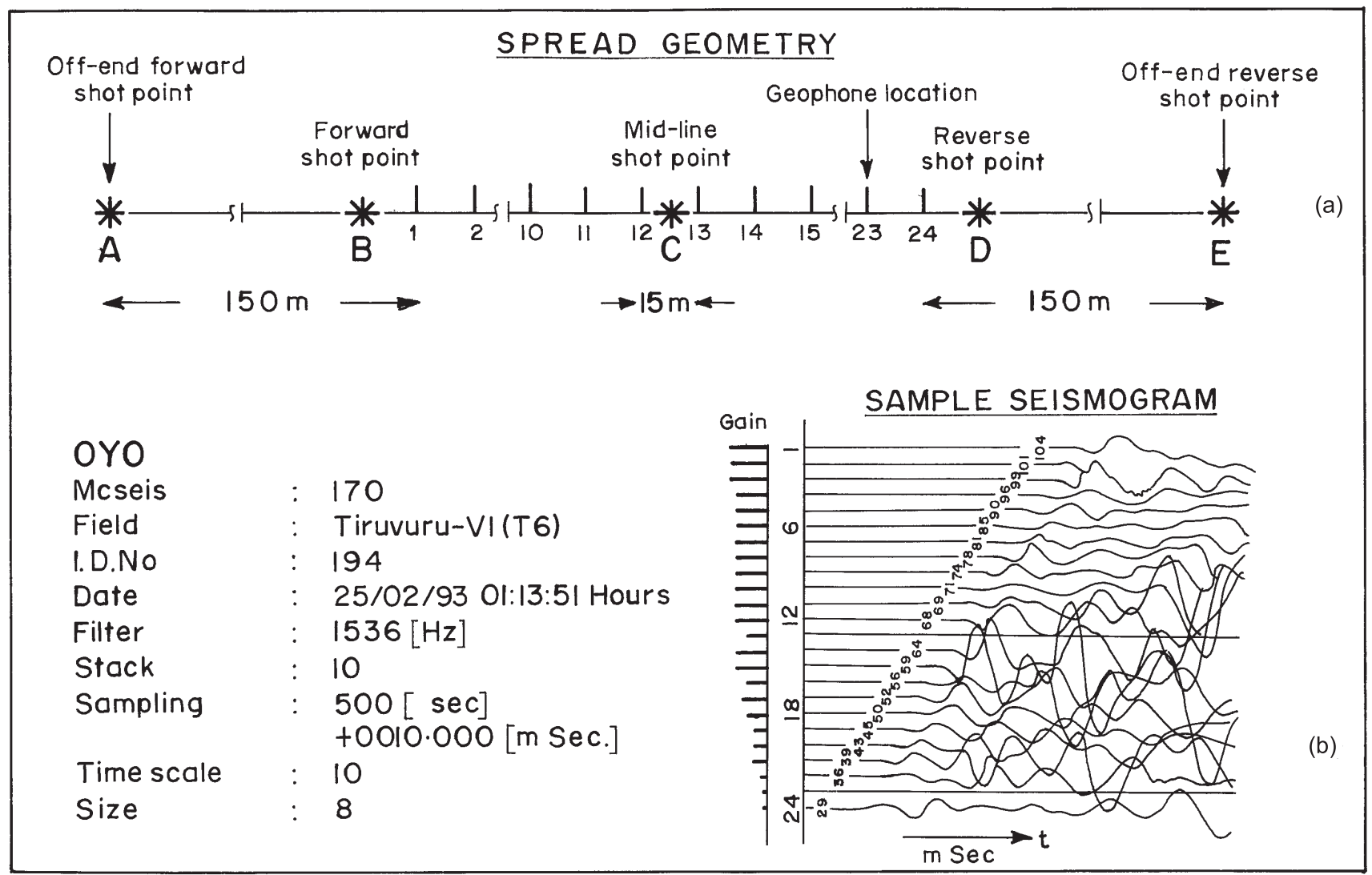

Figure 3. (a) Spread geometry of seismic traverses; (b) Sample seismogram of traverse T6.

method is more useful in groundwater investigations in comparison with reflection method because it generally aims at determining shallow subsurface structures and fractured zones, if any, in the bedrock (Sigmund 1990). An investigation employing refraction seismic method was carried out to understand the structures favourable for groundwater potentiality. Deep aquifers of fractured biotite gneiss within the bedrock below sandstone have been investigated for possible potential groundwater locations.

In the present study, 8 traverses along the profileB (figure 2) each of $345 \mathrm{~m}$ in length were carried out using 24 channel digital stacking Mc-Seis-170, model-1119 refraction seismograph (OYO Corporation, Japan). Geophones used for the survey were of vertical component type whose natural frequency is $14 \mathrm{~Hz}$ with a spacing of $15 \mathrm{~m}$ at an offset of $150 \mathrm{~m}$. The seismic waves were generated by a weight dropper called elastic wave generator (EWG) of Bison Instruments Inc., USA. Forward and reverse shooting procedure was adapted to ensure reliability of the data and to investigate dipping refractors, if any. For each profile there were 5 shots, two for each forward and reverse and one at the centre. The spread geometry of seismic survey and a sample seismogram of traverse T6 are given in figures 3 ( $a$ and $b$ ).

\section{Data interpretation}

The ultimate objective of a refraction seismic survey is to prepare the seismic velocity-depth section specifying the thickness of all layers with the corresponding layer velocities. There are quite a few methods like intercept time method (Gurvich 1972), generalised reciprocal method (Palmer 1981) and plus-minus method (Hagedoorn 1958) available in literature for the determination of layer thickness. In the present case the interpretation is made based on the conventional intercept time method which is simple and more reliable. The depths to the refractors at each geophone location were computed so that the relief of the refractor can be realised along the profile.

To begin with, intercept time $t_{01}$ and $t_{02}$ of the travel time curves $t f_{1}, t r_{1}, t f_{2}$ and $t r_{2}$ (figure 4) were noted from travel time graphs at the shot points SP1, SP2 and SP3 as well as at all geophone locations. Using the following relations, the depths $h_{1}$ and $h_{2}$ were determined for the above shot points. 


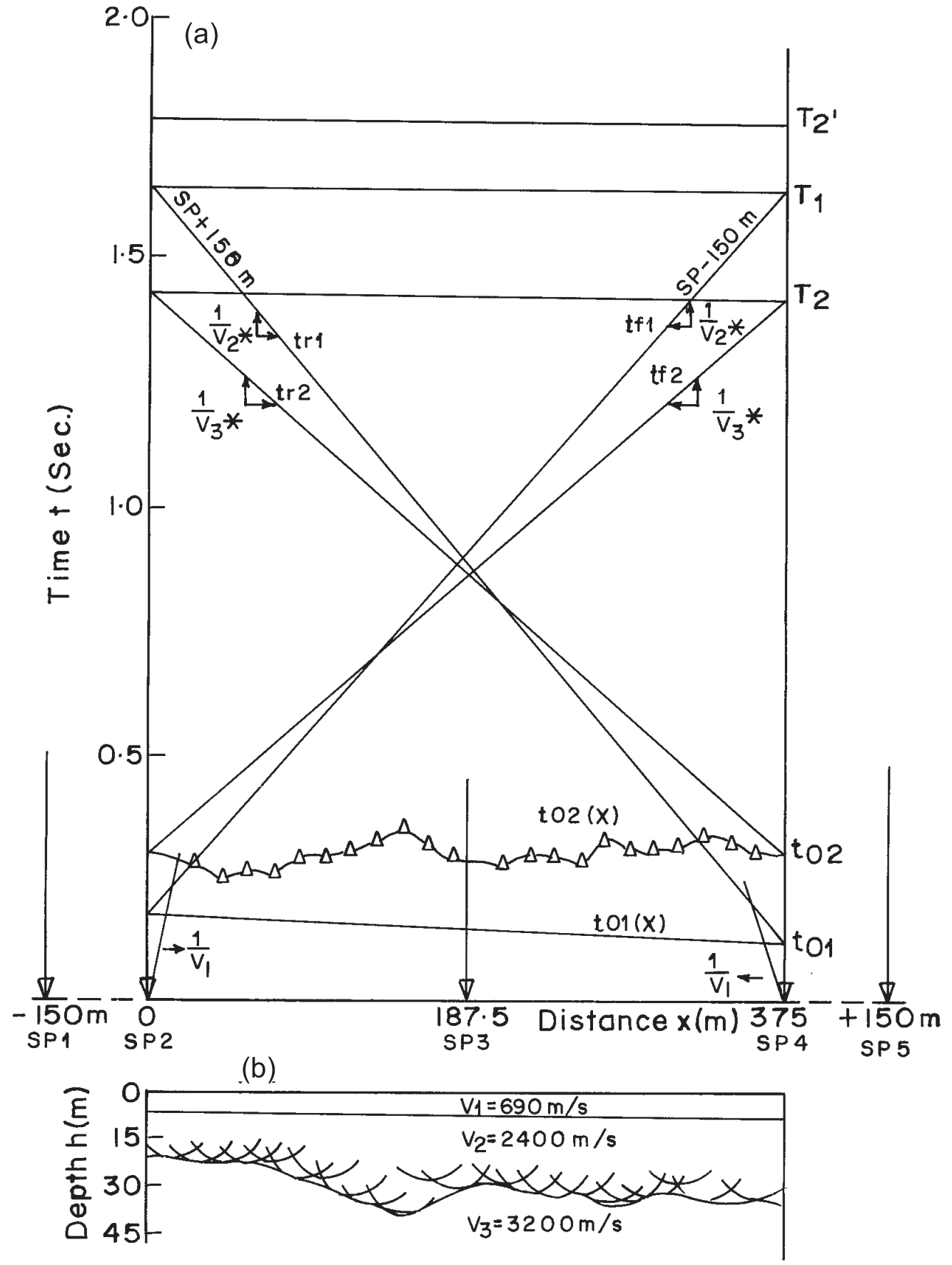

Figure 4. Manual construction of (a) travel time graph; (b) seismic section for the traverse T7.

$h_{1}=K_{1} \times t_{01} \quad$ where $\quad K_{1}=\frac{0.5}{\sqrt{\frac{1}{V_{1}^{2}}-\frac{1}{V_{2}^{2}}}}$

$h_{2}=K_{2} \times t^{*} \quad$ where $\quad K_{2}=\frac{0.5}{\sqrt{\frac{1}{V_{2}^{2}}-\frac{1}{V_{3}^{2}}}}$

$t^{*}=t_{02}-t_{01}$

and $H=h_{1}+h_{2}$ where $H$ is the total thickness.
The velocities $V_{1}, V_{2}$ and $V_{3}$ are obtained as the inverse slope $(\Delta t / \Delta x)$ of the straight lines of direct wave in the case of $V_{1}$ and refracted waves in case of $V_{2}$ and $V_{3}$ as shown in figure $4(\mathrm{a}) . V_{2}^{*}$ and $V_{3}^{*}$ are apparent velocities whereas $V_{1}, V_{2}$ and $V_{3}$ are true velocities. $V_{3}$ is determined as twice the inverse slope $(\Delta \theta / \Delta x)$ of the line obtained by the time difference between the travel time curves $t f_{2}$ and $t_{2}$ (Gurvich 1972). Intercept times for the first and second layers were noted for each geophone 

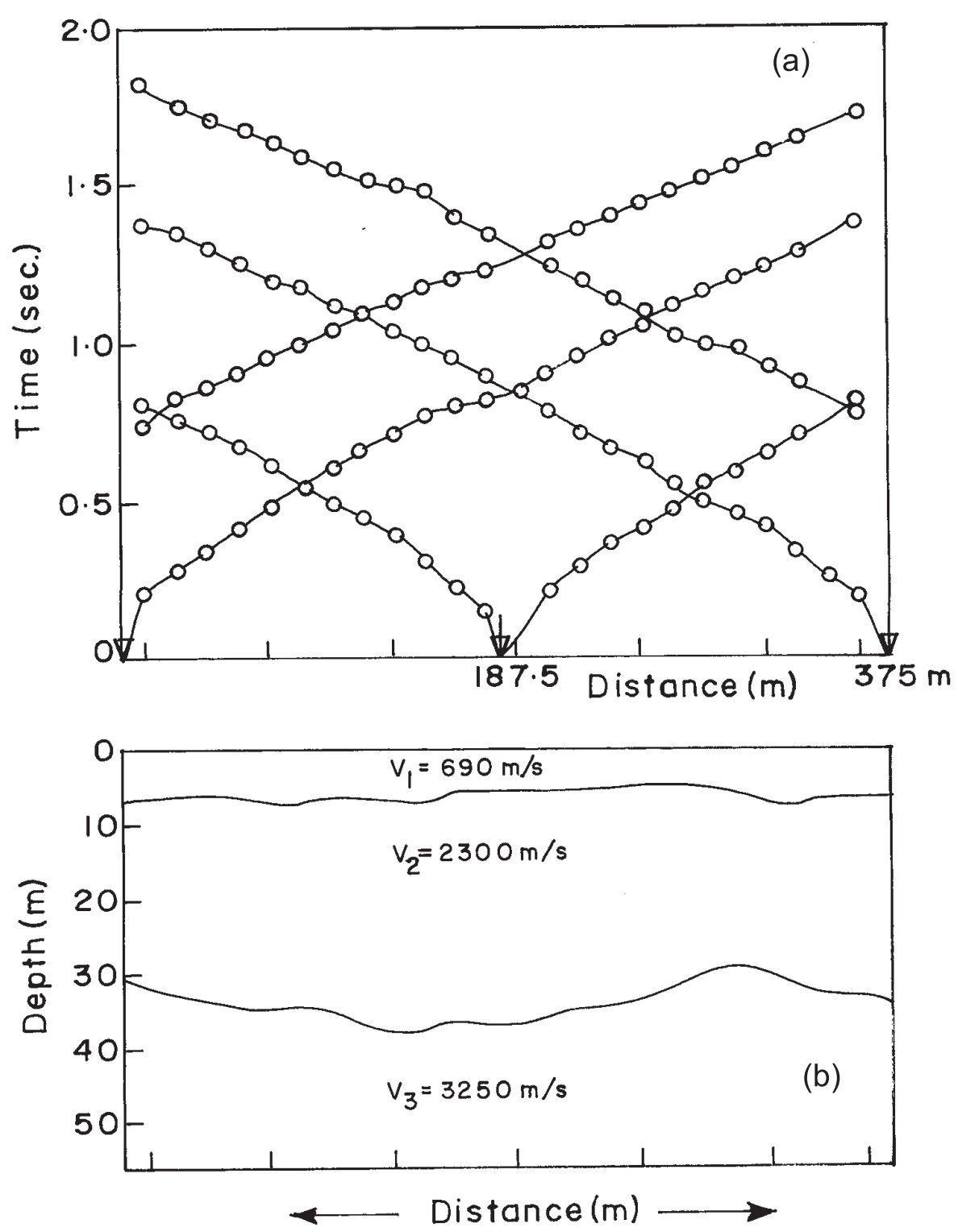

Figure 5. (a) Travel time graph; and (b) seismic section from SIPQC for the traverse T7.

location to construct the intercept time-distance curves with distance ' $x$ ' as $t_{01}(x)$ and $t_{02}(x)$. These two curves for two refractors were utilized to evaluate the depths at every geophone location. Using the method of arcs (Gurvich 1972), the refractor boundary was constructed. The envelop of these arcs forms a smooth curve showing minor undulations in the refractor and the results viz., the depth to first and second refractors and the velocities of layers are evaluated. The refractor relief with small amounts of dip is easily seen from the depth section. The travel time graph and also the seismic section pertaining to traverse $\mathrm{T} 7$ are given in figure 4 .

Followed by manual interpretation, the thickness and velocity of different layers were estimated through modeling using the software Q-Seis of
Grimix and SIPQC version 4.0. These software are quality control programmes meant for quick interpretation of refraction seismic data. Further, these software provide an approximate depth model which can be used for improving accuracy in depth estimation by manual interpretation based on intercept time method. Thus, Q-Seis was used to obtain a first hand approximate estimation of depths (figure 6) followed by SIPQC software to obtain an improvised estimation of depth besides velocities of different layers which are discussed as follows.

To start with, SIPQC computes layer velocities by a closed form least square technique. Then the program uses delay time method to estimate the depth to the top of layer 2 beneath each geophone receiving first arrival with a layer 2 assignment. 


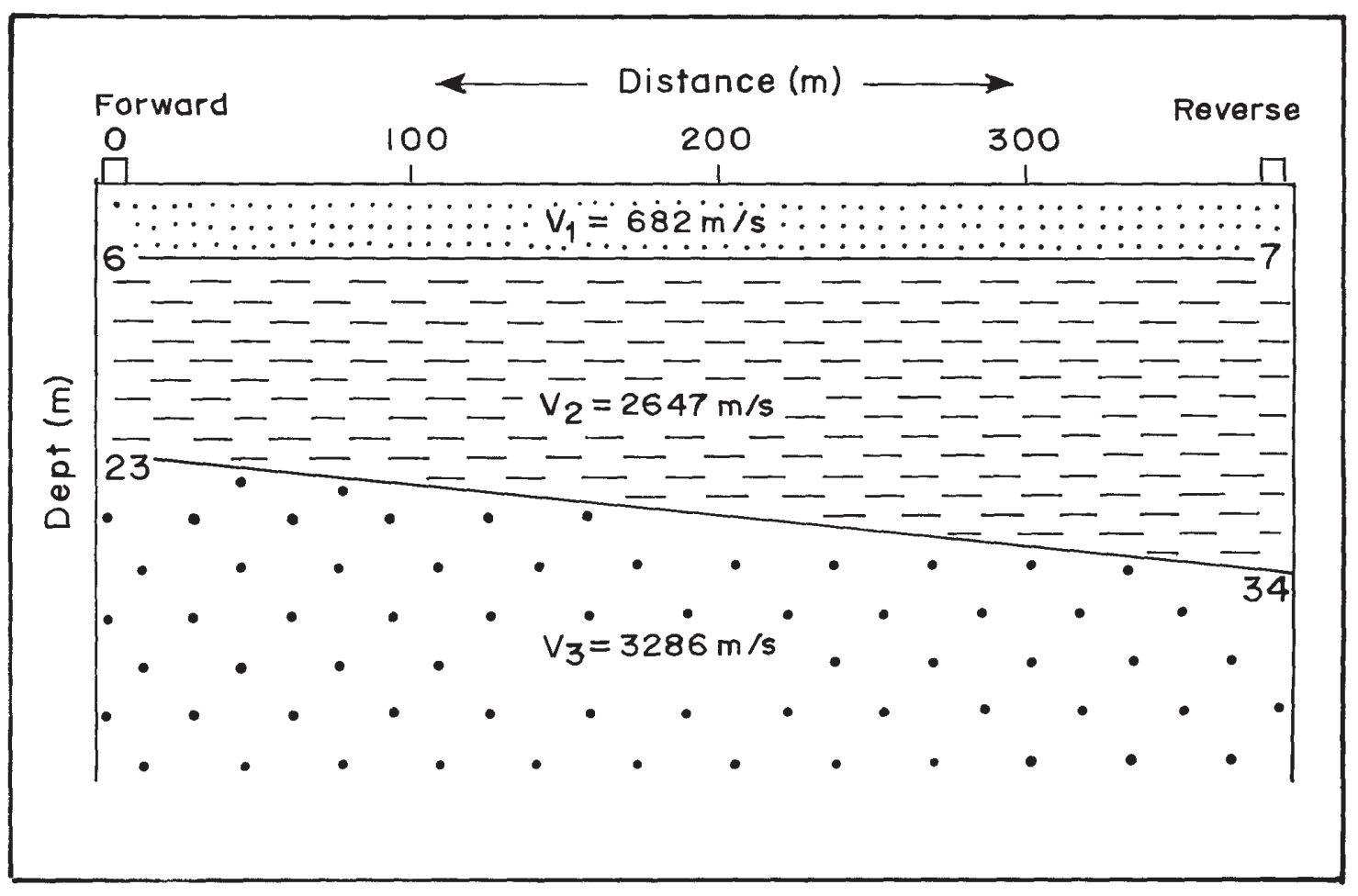

Figure 6. Seismic depth model for traverse T7 based on Q-Seis.

A forward modeling within SIPQC traces the refracted rays of layer 2 from shot points to geophones and computes a travel time for each ray that is traced.

The program then adjusts the layer 2 depths so as to minimize the discrepancies between computed travel times and the first arrival times that were picked up by the resident software. The process of ray tracing and depth adjustments is repeated a few times to obtain an accurate model of the top of layer 2.

For data sets with more than two layers, SIPQC strips away layer 1 and mathematically moves the geophones and shot points down to migrated positions on the top of layer 2. Then it estimates the depth to top layer 3 by using delay time technique and refines the model with three iterations of ray tracing and depth adjustment to reduce the discrepancies between the forward modeled travel times and the measured arrival times.

SIPQC repeats this procedure for deeper layers first by stripping away the upper layers followed by estimating depths to the next deeper layer and thereby refining the depths by ray tracing and model adjustment. The validity of the model depends on the validity and accuracy of the first break picks and layer assignments. If they are correct, the SIPQC model will be correct. Further, error is reduced much if the ground surface is flat and geophones and shot points are along a straight line. The time distance relation and depth section from SIPQC are shown in figure 5 ( $\mathrm{a}$ and $\mathrm{b}$ ) respectively.

The traverses $\mathrm{T} 1$ and $\mathrm{T} 3$ are across the biotite gneisses whereas traverses $\mathrm{T} 7$ and $\mathrm{T} 8$ are across sandstone formation. Traverse T4 is over the contact of both the formations. It is to be noted that the results of manual interpretation of traverse $\mathrm{T} 7$ based on intercept time method (figure 4) is almost equal to the software based interpretation as seen from figure 6 and figure 5 ( $a$ and $b$ ). Further, some low velocity pockets were also delineated which reflect bedrock fractures. Along the traverses T3 and $\mathrm{T} 1$ some low velocity zones (LVZ) were identified between the zones of high velocity of $4210 \mathrm{~m} / \mathrm{s}$. These low velocity zones are of interest for groundwater exploration. The depth to the contacts may be around 50 to $60 \mathrm{~m}$ and the same could not be ascertained due to the limited length of profiles and offset.

From the available three lithological sections (from bore wells, figure 7) only section BW3 near Tiruvuru (extreme north) is compared for layer thickness obtained from both seismic and electrical methods and are found in close agreement with litholog section (figure 7). Above all, the actual depth from bore well coincides with the layer thickness obtained by interpretation of electrical as well as seismic data near the traverse T1 (figure 7). The 


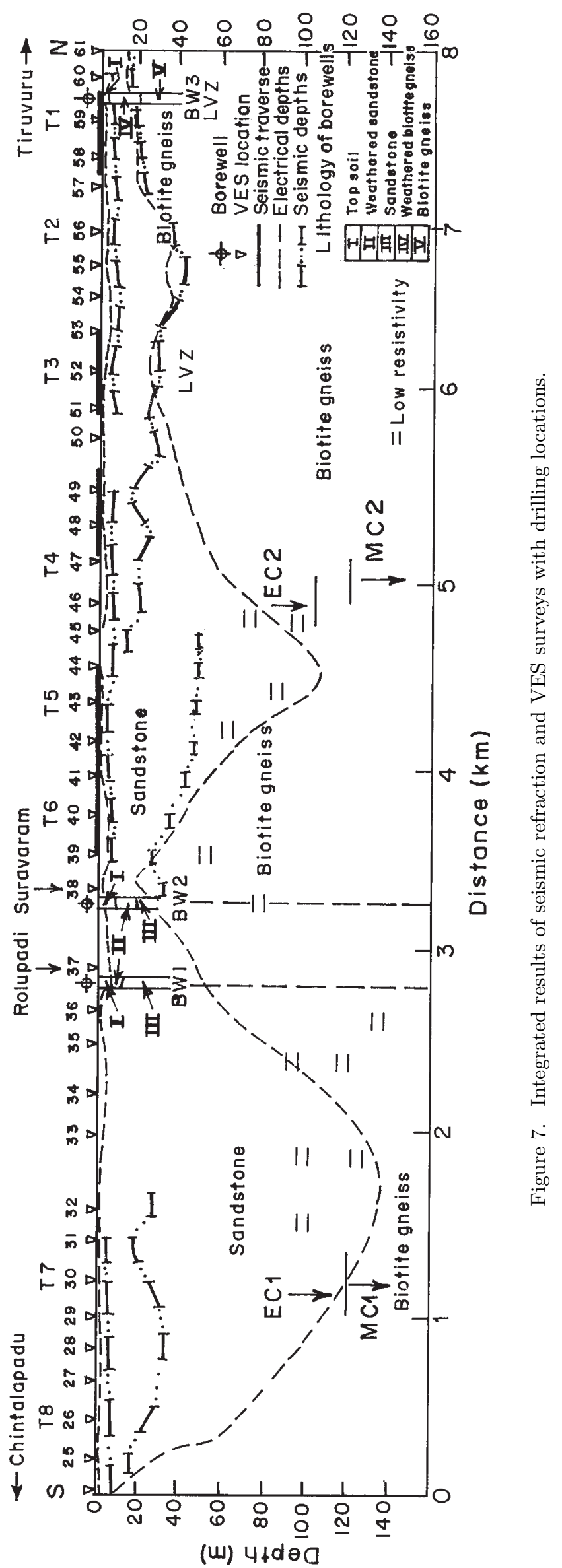


numbers marked from $\mathrm{S}$ to $\mathrm{N}$ in the figure 7 refer to the vertical electrical sounding points. The interpretation of VES at 59 and 60 approximately yield the thickness as $20 \mathrm{~m}$ (Chary 2003). In figure 7, MC1 and $\mathrm{MC} 2$ and $\mathrm{EC} 1$ and $\mathrm{EC} 2$ are the contacts of weathering based on the magnetic and electrical investigation.

\section{Conclusions}

Spatial location of geological contacts between two formations associated with the outlier near Tiruvuru is established based on seismic refraction method. Depths to basement and fracture within the contacts are also brought out. The results were examined by correlating the geophysical signals with the available geology of the area and was found to be a favourable zone for further exploration and exploitation of groundwater. Refraction seismic studies proved to be highly useful in accurately determining the thickness of various layers. Certain low velocity pockets which are favourable for groundwater accumulation were also identified.

\section{Acknowledgements}

The authors wish to record their sincere thanks to the reviewers for their very constructive suggestions to improve the text. Mr. T Seshunarayana, Scientist, National Geophysical Research Institute, Hyderabad is thanked for his help in interpretation. One of the authors Y Srinivas would like to thank the Council of Scientific and Industrial Research (CSIR), New Delhi for financial support.

\section{References}

Chary M N 2003 Integrated geophysical methods for groundwater exploration near Tiruvuru, Krishna district, Andhra Pradesh; Ph.D Thesis submitted to O.U, Hyderabad.

Gurvich I 1972 Seismic Prospecting (Moscow, USSR: Mir Publishers)

Hagedoorn J G 1958 The plus-minus method of interpreting seismic refraction sections: Presented at the fifteenth meeting of the European Association of Exploration Geophysicists, held in London.

Krishnan M S 1960 Geology of India and Burma (Madras: Higginbothams, Pvt. Ltd.)

Murthy B V S, Varaprasada Rao S M and Bhimashankaram V L S 1982 Structure and geology of the Munneru valley as inferred from gravity and magnetic surveys; J. Indian Acad. Geosciences 24 p. 5-12

Murthy B V S, Gyasuddin Mohammed and Sitaramaiah S 1983 An objective approach to mineral exploration through geophysical mapping- A study of Pakhal Cuddapah tract of A.P., India; Geophys. Res. Bull. 21 p. 113-29

Palmer D 1981 An introduction to the generalized reciprocal method of seismic refraction interpretation; Geophysics 46 pp. $1508-1518$

Ramam K, Kumar K V, Tata S N and Chary M N 2000 Report on geophysical investigations for groundwater in the upland areas of Krishna district, Andhra Pradesh; Central Ground Water Board.

Ramamohan Rao K 1979 Study of the geology of Vanadiferous magnetite deposit of Tiruvuru, Krishna district, A.P; Ph.D. thesis, Osmania University, Hyderabad.

Sarma B K, Suryabhanu K and Rama Rao M S V 1968 Report on geophysical investigations for groundwater in parts of Krishna and west Godavary districts; GSI report (unpublished).

Shyam Prasad B 1995 Groundwater resources and development prospects in Krishna district, Andhra Pradesh; A report submitted to Govt. of India

Sigmund D S 1990 Detection of distressed rock and potential collapse feature above old mine workings by the seismic refraction method; In: SEG by S.H. Ward, 3 pp. 281-288

Venkataraman A P R 1961 Report on groundwater investigations in Tiruvuru panchayat samithi, Krishna district (Geological Survey of India).

Ziauddin 1954 Geological Survey of India, Records 86 Part I 